\title{
$\gamma$-Glutamyl hydrolase modulation significantly influences global and gene-specific DNA methylation and gene expression in human colon and breast cancer cells
}

\author{
Sung-Eun Kim • Toshinori Hinoue • Michael S. Kim • \\ Kyoung-Jin Sohn • Robert C. Cho $\cdot$ Peter D. Cole • \\ Daniel J. Weisenberger $\cdot$ Peter W. Laird $\cdot$ Young-In Kim
}

Received: 31 July 2014/Accepted: 17 November 2014/Published online: 13 December 2014

(c) Springer-Verlag Berlin Heidelberg 2014

\begin{abstract}
Glutamyl hydrolase (GGH) plays an important role in folate homeostasis by catalyzing hydrolysis of polyglutamylated folate into monoglutamates. Polyglutamylated folates are better substrates for several enzymes involved in the generation of $S$-adenosylmethionine, the primary methyl group donor, and hence, GGH modulation may affect DNA methylation. DNA methylation is an important epigenetic determinant in gene expression, in the maintenance of DNA integrity and stability, and in chromatin modifications, and aberrant or dysregulation of DNA methylation has been mechanistically linked to the development of human diseases including cancer. Using a recently developed in vitro model of GGH modulation in
\end{abstract}

Electronic supplementary material The online version of this article (doi:10.1007/s12263-014-0444-0) contains supplementary material, which is available to authorized users.

S.-E. Kim · R. C. Cho · Y.-I. Kim

Department of Nutritional Sciences, University of Toronto,

Toronto, ON M5S 1A8, Canada

S.-E. Kim · M. S. Kim · K.-J. Sohn · Y.-I. Kim

Keenan Research Centre for Biomedical Science of

St. Michael's Hospital, Toronto, ON M5B 1T8, Canada

\section{S.-E. Kim $(\square)$}

Keenan Research Centre for Biomedical Science of

St. Michael's Hospital, Room 516, 209 Victoria Street,

Toronto, ON M5B 1T8, Canada

e-mail: sungeun.kim@alum.utoronto.ca

T. Hinoue - P. W. Laird

Center for Epigenetics, Van Andel Research Institute,

Grand Rapids, MI 49503-2518, USA

K.-J. Sohn · Y.-I. Kim

Department of Medicine, University of Toronto, Toronto,

ON M5S 1A8, Canada
HCT116 colon and MDA-MB-435 breast cancer cells, we investigated whether GGH modulation would affect global and gene-specific DNA methylation and whether these alterations were associated with significant gene expression changes. In both cell lines, GGH overexpression decreased global DNA methylation and DNA methyltransferase (DNMT) activity, while GGH inhibition increased global DNA methylation and DNMT activity. Epigenomic and gene expression analyses revealed that GGH modulation influenced $\mathrm{CpG}$ promoter DNA methylation and gene expression involved in important biological pathways including cell cycle, cellular development, and cellular growth and proliferation. Some of the observed altered gene expression appeared to be regulated by changes in CpG promoter DNA methylation. Our data suggest that the GGH modulation-induced changes in total intracellular folate concentrations and content of long-chain

\author{
P. D. Cole \\ Department of Pediatrics, Albert Einstein College of Medicine, \\ Bronx, NY 10467, USA \\ D. J. Weisenberger \\ USC Epigenome Center, University of Southern California, \\ Los Angeles, CA 90089-9601, USA \\ D. J. Weisenberger \\ Department of Biochemistry and Molecular Biology, University \\ of Southern California, Los Angeles, CA 90089-9601, USA \\ Y.-I. Kim \\ Division of Gastroenterology, St. Michael's Hospital, Toronto, \\ ON M5B 1W8, Canada
}


folylpolyglutamates are associated with functionally significant DNA methylation alterations in several important biological pathways.

Keywords Folate $\cdot \gamma$-Glutamyl hydrolase $(\mathrm{GGH}) \cdot$ DNA methylation - Gene expression · Colon cancer · Breast cancer

$\begin{array}{ll}\text { Abbreviations } \\ \text { CIMP+ } & \text { CpG island methylator phenotype } \\ \text { CpG } & \text { Cytosine-guanine dinucleotide sequences } \\ \text { DNMT } & \text { DNA methyltransferase } \\ \text { FDR } & \text { False discovery rate } \\ \text { FPGS } & \text { Folylpolyglutamate synthase } \\ \text { 5FU } & \text { 5-Fluorouracil } \\ \text { GGH } & \gamma \text {-Glutamyl hydrolase } \\ \text { MRP } & \text { Multidrug-resistance-associated protein } \\ \text { MTX } & \text { Methotrexate } \\ \text { qRT-PCR } & \text { Quantitative reverse transcriptase-PCR } \\ \text { SAM } & S \text {-Adenosylmethionine } \\ \text { siRNA } & \text { Small-interfering RNA }\end{array}$

\section{Introduction}

Folate, a water-soluble B-vitamin, mediates the transfer of one-carbon units involved in thymidylate and purine biosynthesis and biological methylation reactions (Kim 2007; Shane 2010). Intracellular folate homeostasis is maintained by folylpolyglutamate synthase (FPGS) that facilitates intracellular retention of folate by polyglutamylation and by $\gamma$-glutamyl hydrolase (GGH) that catalyzes the hydrolysis of polyglutamylated folate into monoglutamates, thereby facilitating the export of folate out of the cell (Shane 2010). Polyglutamylated folates are better retained within cells than monoglutamate counterparts and are better substrates for folate-dependent enzymes (Moran 1999).

Folate, in the form of 5-methyltetrahydrofolate, is involved in remethylation of homocysteine to methionine, which is a precursor of $S$-adenosylmethionine (SAM), the primary methyl group donor for most biological methylation reactions including DNA methylation (Kim 2004, 2005; Ly et al. 2012). Folate deficiency and excess have been shown to affect DNA methylation in a gene, site, and cell-specific manner (Ly et al. 2012). DNA methylation is an important epigenetic determinant in gene expression (an inverse relation except for few exceptions), in the maintenance of DNA integrity and stability, in chromatin modifications, and in the development of mutations (Kulis and Esteller 2010). DNA methylation of cytosine in the cytosine-guanine dinucleotide sequences $(\mathrm{CpG})$ is a heritable, tissue- and species-specific, post-synthetic epigenetic modification of mammalian DNA (Kulis and Esteller 2010). Seventy to $80 \%$ of all CpG sites in human DNA are normally methylated (Kulis and Esteller 2010). However, this methylation occurs primarily in the bulk of the genome where $\mathrm{CpG}$ density is low, including exons, noncoding regions, and repeat DNA sites, and allows correct organization of chromatin in active and inactive states (Kulis and Esteller 2010). By contrast, most CpG-rich areas clustered in small stretches of DNA termed "CpG islands", which span the $5^{\prime}$ end of approximately half of the human genes including the promoter, untranslated region, and exon 1 , are unmethylated in normal cells, thereby allowing transcription (Herman and Baylin 2003; Kulis and Esteller 2010). When methylated, $\mathrm{CpG}$ islands can correlate with stable heritable transcriptional silencing (Herman and Baylin 2003; Kulis and Esteller 2010). DNA methylation is a dynamic process between active methylation, mediated by CpG DNA methyltransferases (DNMT) using SAM as the methyl donor, and removal of methyl groups from 5-methylcytosine residues by both passive and active mechanisms (Kulis and Esteller 2010; Li 2000). After transfer of the methyl group, SAM is converted to $S$-adenosylhomocysteine, a potent inhibitor of most SAM-dependent methyltransferases (Kulis and Esteller 2010; Li 2000).

Polyglutamylation is important in DNA methylation considering that polyglutamylated folates are better substrates for methylenetetrahydrofolate reductase and methionine synthase, both of which are involved in the generation of SAM (Kim 2007; McGuire and Bertino 1981; Moran 1999). Therefore, GGH modulation may affect DNA methylation by changes in total intracellular folate concentrations and by alterations in contents of polyglutamylated folate cofactors with consequent functional ramifications. Aberrant or dysregulation of DNA methylation is mechanistically related to the development of several human diseases including cancer, and hence, GGH overexpression/inhibition may have significant implications in human health and disease via its effects on DNA methylation (Ly et al. 2012). We have recently generated a novel in vitro model of GGH modulation in HCT116 colon and MDA-MB-435 breast cancer cells with predictable functional consequences (Kim et al. 2013). Using this model, we tested the hypothesis that GGH modulation would affect global and gene-specific DNA methylation with consequent functional effects on gene expression.

\section{Materials and methods}

In vitro model of GGH overexpression and inhibition

We have previously developed and functionally characterized an in vitro model of GGH overexpression and 
inhibition in HCT116 colon and MDA-MB-435 breast cancer cells (Kim et al. 2013). Cells overexpressing GGH had significantly higher GGH protein expression and activity, lower total intracellular folate concentrations, lower content of long-chain folylpolyglutamates, slower growth rate, lower thymidylate synthase activity, and lower dihydrofolate reductase protein expression and activity compared with controls expressing endogenous GGH (Kim et al. 2013). In contrast, cells in which GGH is inhibited had significantly lower GGH protein expression and activity, higher concentrations of total intracellular folate, higher content of long-chain folylpolyglutamates, faster growth rate, higher thymidylate synthase activity, and higher dihydrofolate reductase protein expression and activity compared with controls expressing endogenous GGH (Kim et al. 2013). Cells were grown in RPMI-1640 medium (Invitrogen) containing $2.3 \mu \mathrm{mol} / \mathrm{L}$ folic acid supplemented with $10 \%$ fetal bovine serum, $500 \mu \mathrm{g} / \mathrm{mL}$ Geneticin $^{\circledR}, 50 \mathrm{U} / \mathrm{mL}$ penicillin with $50 \mu \mathrm{g} / \mathrm{mL}$ streptomycin, and $0.25 \mu \mathrm{g} / \mathrm{mL}$ fungizone amphotericin B. Cell cultures were maintained at $37{ }^{\circ} \mathrm{C}$ in $5 \% \mathrm{CO}_{2}$. Cells were harvested at $80 \%$ confluence and were processed for subsequent analyses.

\section{Global DNA methylation analysis}

Total genomic DNA was extracted by a standard technique using proteinase $\mathrm{K}$ followed by organic extraction (Laird et al. 1991). The size of DNA estimated by agarose gel electrophoresis was $>20 \mathrm{~kb}$ in all instances. The final preparations had an $\mathrm{A}_{260}$ to $\mathrm{A}_{280}$ ratio between 1.8 and 2.0 and were free of RNA and protein contaminations. The concentration of each DNA sample was determined as the mean of three independent spectrophotometric readings. Global $\mathrm{CpG}$ DNA methylation was determined by the in vitro methyl acceptance assay using [ ${ }^{3} \mathrm{H}$-methyl] SAM (New England Nuclear) as a methyl donor and a prokaryotic CpG DNMT, Sss1 (New England Biolabs), as previously described (Sohn et al. 2004). The manner in which this assay is performed produces an inverse relationship between the endogenous DNA methylation status and exogenous $\left[{ }^{3} \mathrm{H}\right.$-methyl] incorporation. All analyses were performed in quadruplicate and repeated using two independent cell lysates.

\section{DNMT activity assay}

Total cellular CpG DNMT activity was measured by incubating cell lysate containing $10 \mu \mathrm{g}$ of protein with $0.5 \mu \mathrm{g}$ of poly[d(I-C).d(I-C)] template (Sigma-Aldrich), $3 \mu \mathrm{Ci}\left[{ }^{3} \mathrm{H}\right]-\mathrm{SAM}$ (New England Nuclear), and lysis buffer in a total volume of $20 \mu \mathrm{L}$ for $2 \mathrm{~h}$ at $37^{\circ} \mathrm{C}$ as previously described (Sohn et al. 2004). Each reaction was performed in triplicate, and the assay was repeated three times.

Gene-specific promoter CpG DNA methylation analyses

The Illumina Infinium HumanMethylation27 (HM27) BeadChip (Illumina) was used to interrogate the DNA methylation status of 27,578 individual $\mathrm{CpG}$ sites located at promoter regions of 14,495 genes (Bibikova et al. 2009). Briefly, $1 \mu \mathrm{g}$ of genomic DNA was bisulfite-converted using the EZ-96 DNA Methylation Kit (Zymo Research) according to the manufacturer's protocol. Unmethylated cytosines are deaminated to uracil in the presence of bisulfite, while methylated cytosines are refractory to the effects of bisulfite and remain as cytosine. The bisulfite conversion included a thermocycling program with a short denaturation step (16 cycles of $95{ }^{\circ} \mathrm{C}$ for $30 \mathrm{~s}$ followed by $50{ }^{\circ} \mathrm{C}$ for $1 \mathrm{~h}$ ). The amount of bisulfite-converted DNA and completeness of bisulfite conversion were assessed using a panel of MethyLight-based quality control reactions as previously described (Campan et al. 2009). All of the samples passed the quality control tests and were used for the Infinium DNA methylation assay. A measure of the level of DNA methylation at each $\mathrm{CpG}$ site was scored as beta $(\beta)$-values. DNA methylation $\beta$-values represent the ratio of the intensity of the methylated bead type to the combined locus intensity ranging from 0 to 1 . Values close to 0 indicate low levels of DNA methylation, while values close to 1 indicate high levels of DNA methylation (Bibikova et al. 2009). The detection $P$-values measure the difference of the signal intensities at the interrogated $\mathrm{CpG}$ site compared with those from a set of 16 negative control probes embedded in the assay. We identified all data points with a detection $P$-value $>0.05$ as not statistically significantly different from background measurements and therefore were not considered trustworthy measures of DNA methylation. These data points were replaced by "NA" values as previously described (Noushmehr et al. 2010). Statistical analysis and data visualization were carried out using the R/Bioconductor software packages (http://www.bioconductor.org). The Illumina Infinium DNA methylation $\beta$-values were represented graphically using a heatmap, generated by the R/Bioconductor packages called heatmap.plus and MATLAB. The annotation for Illumina Infinium HM27 probes used in this study is presented in Supplement 1.

DNA hyper- or hypomethylation was calculated for each HM27 probe by subtracting the $\beta$-value of the corresponding control from the $\beta$-value of cells expressing the sense GGH cDNA (Sense) or cells transfected with the GGH-targeted small-interfering RNA (siRNA). We determined the $\beta$-value difference of 0.2 as having $99 \%$ 
confidence based on intra- and inter-assay variations (Bibikova et al. 2009).

\section{Gene expression analysis}

RNA was isolated using the RNeasy Microarray Tissue Mini Kit (Qiagen) according to the manufacturer's protocol. Total RNA was assessed for the RNA quality verification and microarray hybridization. The Agilent 2100 Bioanalyzer (Agilent Technologies), a microfluidics-based platform, was used for sizing, quantification, and quality of RNA. The RNA Integrity Number score was generated on the Agilent software. For the microarray analysis, the RNA quality for all of the samples had a RNA Integrity Number score $\geq 7$.

The Illumina ${ }^{\circledR}$ TotalPrepTM-96 RNA Amplification Kit (Ambion) was used for generating biotinylated, amplified cRNA according to the manufacturer's protocol. The cRNA yield was quantified by NanoDrop (NanoDrop Technologies). A total of $750 \mathrm{ng}$ of purified biotinylated cRNA generated from the samples were randomized in triplicate and used to hybridize onto the Illumina HumanHT-12 v4.0 BeadChip (Illumina). Each array on this BeadChip targets 31,335 annotated genes and includes 47,231 probes designed to cover content from NCBI RefSeq Release 38 (November 7, 2009), as well as legacy UniGene content. Twelve samples were hybridized to one slide for higher throughput and reduced sample-to-sample variability since gaskets separate each array. The BeadChip was incubated at $58^{\circ} \mathrm{C}$, with rotation speed 5 for $18 \mathrm{~h}$ for hybridization. After washing and staining, each BeadChip was scanned on the iScan (Illumina), a laser-based imaging system with two lasers (red: Cy5 and green: Cy3) for detecting fluorescence information. The intensity files were quantified in GenomeStudio $^{\circledR}$ (Illumina, version 2010.2) to generate intensity measurements without normalization algorithms.

For the gene expression analysis, data were checked for overall quality using $\mathrm{R}$ version 2.13 .2 with the Bioconductor framework and the LUMI package (http://www. bioconductor.org). Data were imported in GeneSpring GX 11.5 (Agilent Technologies) and normalized using a standard quantile-based normalization followed by a "per probe" median-centered normalization. All data were $\log _{2^{-}}$ transformed for analysis and visualization. Data were initially filtered in order to remove any confounding effects on subsequent analyses of probes with no signal. Only probes in the upper 80th percentile of the distribution of intensities in $100 \%$ of samples from any of the groups were retained following filtering. Normalization and data filtering were performed separately for each subset of samples being used in a particular analysis. For comparisons between cells expressing the sense GGH (Sense) and control (Control-S) and between cells transfected with the GGH-targeted siRNA (siRNA) and control (Control-si), an unpaired $t$-test using a false discovery rate (FDR) Benjamini and Hochberg multiple testing correction with a $P$-value cutoff of 0.05 was performed.

Integrated analysis of DNA methylation and gene expression data

We merged the DNA methylation and gene expression data sets using Entrez Gene IDs for the integrated analysis to identify genes for which the differential expression might have been influenced by DNA methylation in response to GGH modulation. We used a $\beta$-value difference $(|\Delta \beta|)$ of 0.20 as a threshold for differential DNA methylation between Sense and Control-S and between siRNA and Control-si. This threshold of $|\Delta \beta|=0.20$ was determined previously as a stringent estimate of $\Delta \beta$ detection sensitivity across the range of $\beta$-values (Bibikova et al. 2009). Gene expression data with (1) a fold change greater or less than 1.3 and (2) a one-way ANOVA with a Benjamini and Hochberg-corrected $P$-value $\leq 0.05$ were used for integrated analysis. We set 1.3 as a fold change not to overlook small changes in response to GGH modulation as we identified a small number of genes differentially expressed especially in the GGH-modulated HCT116 cells.

\section{Functional analysis}

The functional analysis was performed using Ingenuity Pathway Analysis (IPA, Ingenuity ${ }^{\circledR}$ Systems; http://www. ingenuity.com) to identify biological functions and/or diseases that were most significant to genes differentially methylated and/or regulated in each system. Genes with a threshold of $|\Delta \beta|=0.20$ and/or fold change of $|1.3|$ and that were associated with biological functions and/or diseases in the Ingenuity Knowledge Base were considered for the analysis. The right-tailed Fisher's exact test was used to calculate $P$-values in determining the probability that each biological function and/or disease assigned to that data set is due to chance alone.

\section{Quantitative reverse transcriptase-PCR (qRT-PCR)}

qRT-PCR was performed to confirm the data obtained from gene expression analysis using the Illumina HumanHT-12 v4.0 BeadChip. Template RNA was reversely transcribed to cDNA using the QuantiTect Reverse Transcription Kit (Qiagen). Selected primer sequences were synthesized by the Integrated DNA Technologies and are presented in Supplement 2. The reactions were run in triplicate on MicroAmp Optical 384-well plates (Applied Biosystems, Life Technologies), and their amplifications were tracked 
by SYBR Green fluorescent dye (Applied Biosystems, Life Technologies). Completed plates were spun at 1,200 rpm for $2 \mathrm{~min}$ at $4{ }^{\circ} \mathrm{C}$ and then placed in the ViiA-7TM RealTime PCR System (Applied Biosystems, Life Technologies). The reaction conditions for stage one were as follows: $2 \mathrm{~min}$ at $50{ }^{\circ} \mathrm{C}$, followed by $10 \mathrm{~min}$ at $95^{\circ} \mathrm{C}$ to activate the polymerase. This stage was followed by 40 cycles beginning with $15 \mathrm{~s}$ at $95^{\circ} \mathrm{C}$ to denature the target strand followed by $1 \mathrm{~min}$ at $60{ }^{\circ} \mathrm{C}$ to allow for the polymerase to anneal and extend the target strand. Finally, a melt curve followed consisting of $15 \mathrm{~s}$ at $95{ }^{\circ} \mathrm{C}$ then $1 \mathrm{~min}$ at $60{ }^{\circ} \mathrm{C}$. Relative gene expression data were analyzed using the comparative threshold $\left(C_{\mathrm{t}}\right)$ method as described previously (Livak and Schmittgen 2001).

\section{Statistical analysis}

For global DNA methylation, DNMT activity, and qRT-PCR analyses, comparisons between Sense and Control-S (GGH overexpression) and between siRNA and Control-si (GGH inhibition) were determined using the Student's $t$-test function of SPSS Statistics 17.0 (IBM SPSS, Chicago, IL). The results were considered statistically significant if two-tailed $P$-values were $<0.05$.

\section{Results}

Global DNA methylation and DNMT activity

In both HCT116 and MDA-MB-435 cells, GGH overexpression was associated with significantly lower global DNA methylation (HCT116, $16 \%$ lower, $P=0.024$, Fig. 1a; MDA-MB-435, $22 \%$ lower, $P<0.001$, Fig. 1c) and lower DNMT activity (HCT116, $66 \%$ lower, $P<0.001, \quad$ Fig. 1e; MDA-MB-435, $26 \%$ lower, $P=0.003$, Fig. 1g) compared with controls expressing endogenous GGH.

In contrast, GGH inhibition showed significantly higher global DNA methylation (HCT116, $15 \%$ higher, $P=0.013$, Fig. 1b; MDA-MB-435, $7 \%$ higher, $P=0.013$, Fig. 1d) and higher DNMT activity (HCT116, $47 \%$ higher, $P<0.001$, Fig. 1f; MDA-MB-435, $27 \%$ higher, $P=0.002$, Fig. 1h) compared with controls expressing endogenous GGH in both cell lines.

Effect of GGH modulation on gene-specific $\mathrm{CpG}$ promoter DNA methylation

We then determined whether GGH modulation would affect gene-specific DNA methylation, thereby identifying biological pathways that are primarily affected by the GGH modulation-induced DNA methylation alterations, in
HCT116 and MDA-MB-435 cell lines. Scatter plots of DNA methylation $\beta$-values showed differentially methylated loci between cells overexpressing GGH (Sense) and corresponding controls (Control-S) and between cells with GGH inhibition (siRNA) and corresponding controls (Control-si). MDA-MB-435 breast cancer cells showed more $\mathrm{CpG}$ methylation alterations in response to GGH modulation than HCT116 colon cancer cells (Supplement 3).

\section{Genes differentially methylated in the GGH-modulated HCT116 cells}

In the HCT116 cell line, we identified 905 genes that were differentially methylated (546 hypermethylated and 359 hypomethylated) in response to GGH overexpression, while 1,869 genes were differentially methylated (998 hypermethylated and 871 hypomethylated) in response to GGH inhibition (Fig. 2a). We performed a functional analysis using IPA to identify biological and disease processes involving the GGH modulation-induced differentially methylated genes in each system, and these results are presented in Supplement 4. In the GGH-overexpressed HCT116 cells, the hypermethylated genes were associated with cell morphology, cellular development, and antigen presentation, while the hypomethylated genes were involved in molecular transport, cellular assembly and organization, and cell-to-cell signaling and interaction (Supplement 4). As for the GGH-inhibited HCT116 cells, major function categories of the hypermethylated genes included cell-to-cell signaling and interaction, amino acid metabolism, and drug metabolism, whereas those of the hypomethylated genes consisted of lipid metabolism, molecular transport, and small molecule biochemistry (Supplement 4).

\section{Genes differentially methylated in the GGH-modulated MDA-MB-435 cells}

In the MDA-MB-435 cell line, we identified 2,394 genes that were differentially methylated (1,058 hypermethylated and 1,336 hypomethylated) in response to GGH overexpression, while 2,666 genes were differentially methylated (1,122 hypermethylated and 1,544 hypomethylated) in response to GGH inhibition (Fig. 2a). Genes with functions relating to cell-to-cell signaling and interaction, cellular movement, and molecular transport were differentially methylated in the GGH-overexpressed MDA-MB-435 cells (Supplement 4). In the GGH-inhibited MDA-MB-435 cells, the hypermethylated genes were associated with cellular movement, cell-to-cell signaling and interaction, and cell morphology, while the hypomethylated genes were involved in cell signaling, molecular transport, and vitamin and mineral metabolism (Supplement 4). 
Global DNA methylation

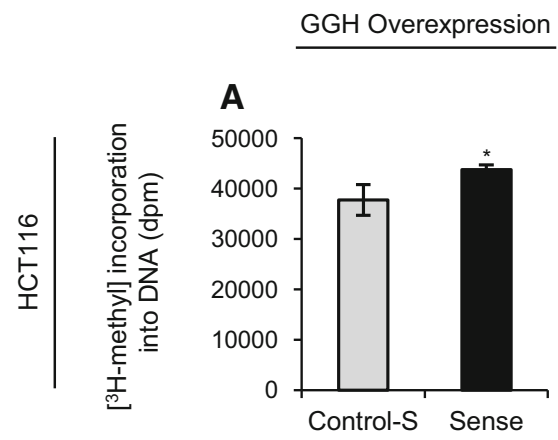

C

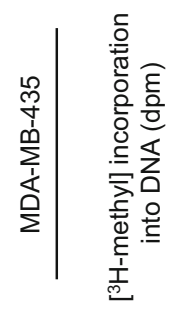

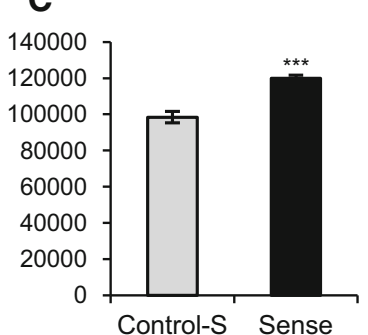

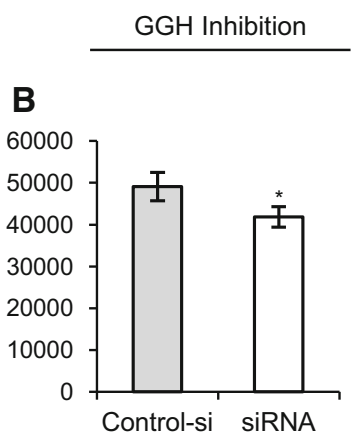

D

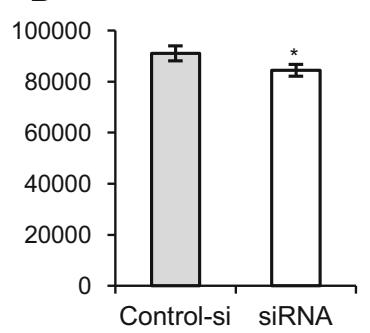

DNMT activity

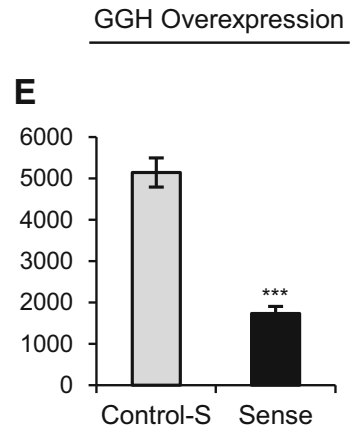

G

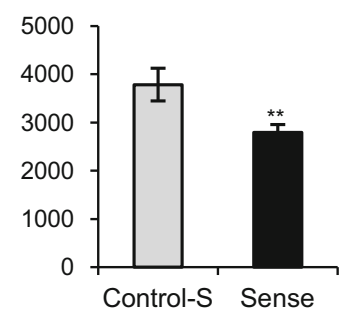

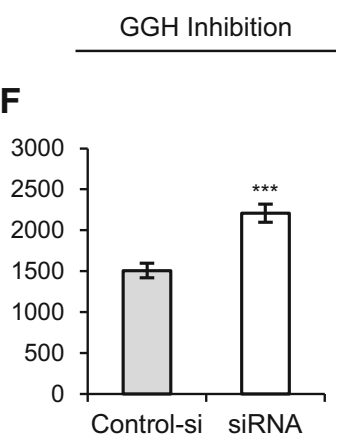

H

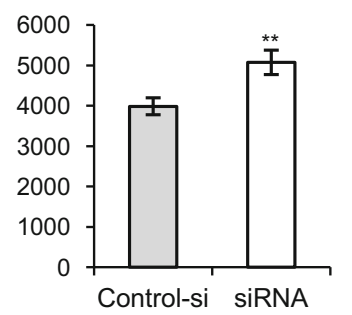

Fig. 1 Effects of GGH modulation on global DNA methylation and DNMT activity in HCT116 and MDA-MB-435 cells. In both cell lines, GGH overexpression was associated with significantly lower global DNA methylation (HCT116, a; MDA-MB-435, c) and lower DNMT activity (HCT116, e; MDA-MB-435, g) compared with controls expressing endogenous GGH, whereas GGH inhibition showed significantly higher global DNA methylation (HCT116, b; MDA-MB-435, d) and higher DNMT activity (HCT116, f; MDAMB-435, h) compared with controls expressing endogenous GGH. The in vitro methyl acceptance assay for global DNA methylation measurement produces an inverse relationship between the endogenous DNA methylation status and exogenous $\left[{ }^{3} \mathrm{H}\right.$-methyl $]$ incorporation into DNA. All analyses were performed in quadruplicate and repeated using two independent cell lysates (a-d). The assay for DNMT activity produces a positive relationship between the endogenous enzyme activity and exogenous $\left[{ }^{3} \mathrm{H}\right.$-methyl] incorporation into DNA. Each reaction was performed in triplicate, and the assay was repeated three times (e-h). Control-S, cells expressing endogenous GGH; Sense, cells transfected with the sense GGH cDNA; Control-si, cells expressing endogenous GGH; siRNA, cells transfected with the GGH-targeted siRNA. $* P<0.05$; $* * P<0.01$; $* * * P<0.001$ compared with corresponding control by the Student's $t$-test. Values are mean $\pm \mathrm{SD}$

were common between two cell lines $\left(P=5.0 \times 10^{-6}\right)$, whereas 129 genes associated with cellular movement, antigen presentation, lipid metabolism, molecular transport, and small molecule biochemistry were commonly hypomethylated in both cell lines $\left(P=8.9 \times 10^{-5}\right)$ (Fig. 2a). The list of top networks generated by mapping the focus genes that displayed differential DNA methylation in both the GGH-modulated HCT116 and MDA-MB435 cells is presented in Supplement 4. The list of genes commonly differentially methylated in both cell lines in response to GGH modulation is presented in Supplement 5 .

\section{Effect of GGH modulation on gene expression}

We investigated whether GGH modulation would affect gene expression profile in HCT116 and MDA-MB-435 cell lines using the Illumina HT-12 platform. Similar to DNA methylation changes, MDA-MB-435 breast cancer cells 
A

Hypermethylation
$(\beta$-value difference $>0.2)$

Hypomethylation

$(\beta$-value difference $<-0.2)$
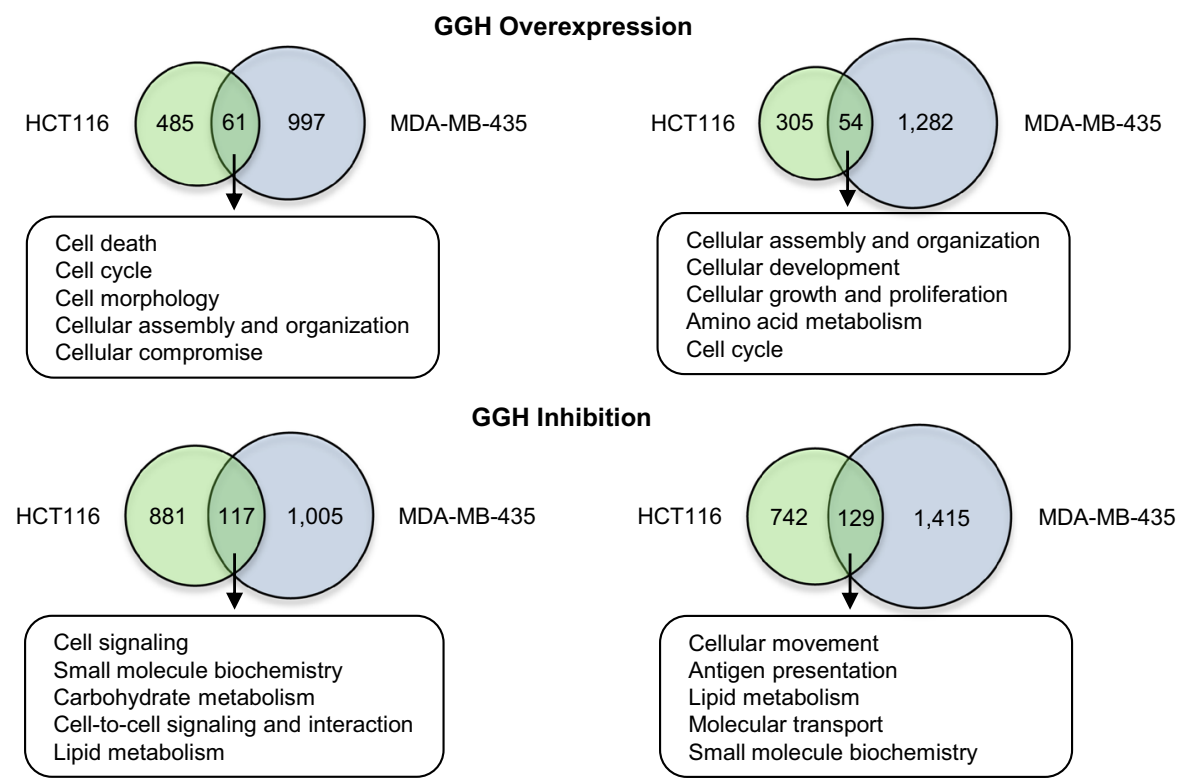

B

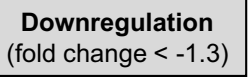

Upregulation (fold change $>1.3$ )

\section{GGH Overexpression}

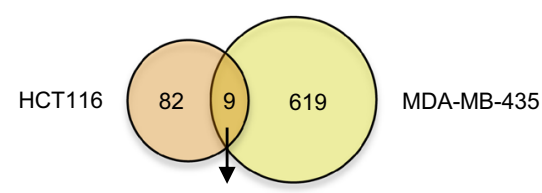

MNS1, TRIM33, PYGL, MCOLN2, AP1S2, SNHG7, INPP4B, TSHZ1, MLPH

Cellular growth and proliferation
Cell cycle
Gene expression
Carbohydrate metabolism
Cellular function and maintenance

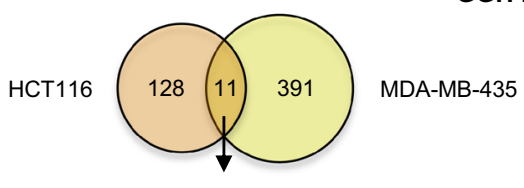

NR4A2, SLC2A3, IGFBP6, TMEM136, ZNF680, ZNF217, IRS1, ARHGEF3, TFAP2A, TCF12, CXXC5

Energy production
Lipid metabolism
Small molecule biochemistry
Cell morphology
Cellular development

Fig. 2 Number of genes differentially methylated and expressed in the GGH-modulated HCT116 and MDA-MB-435 cells. Sixty-one hyper- and 54 hypomethylated genes were common between the HCT116 and MDA-MB-435 cell lines in response to GGH overexpression, whereas 117 hyper- and 129 hypomethylated genes were common between these cell lines in response to GGH inhibition (a). DNA hyper- or hypomethylation was calculated by subtracting the $\beta$-value of corresponding control from the $\beta$-value of Sense or siRNA.

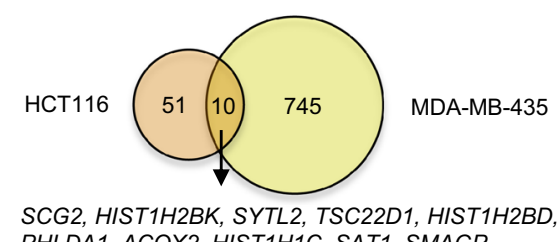

PHLDA1, ACOX2, HIST1H1C, SAT1, SMAGP

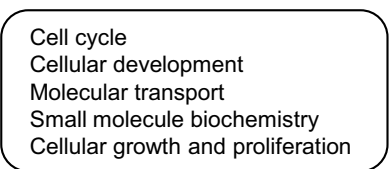

GH Inhibition

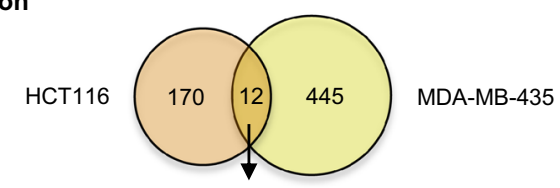

CALB2, NOV, ACOX2, CDKN1A, LOC285735, SLC20A1, IGSF5, AKR1C3, ID2, SRI, MGST1, CKMT1A

Cell cycle
Cell death
Cellular development
Cellular growth and proliferation
Cell morphology

We determined the $\beta$-value difference of 0.2 as having $99 \%$ confidence based on intra- and inter-assay variations (a). Nine down- and 10 upregulated genes were common between two cell lines after GGH overexpression, whereas 11 down- and 12 upregulated genes were common in these cell lines in response to GGH inhibition (b). We determined the number of genes with a fold change $>1.3$ or $<-1.3$ using an unpaired $t$-test with the FDR corrected $P$-value $\leq 0.05$ (b) 
showed more number of genes with altered expression in response to GGH modulation than HCT116 colon cancer cells (Fig. 2b).

\section{Genes differentially expressed in the GGH-modulated HCT116 cells}

In the HCT116 cell line, we identified 152 genes that were differentially expressed (91 downregulated and 61 upregulated) in response to GGH overexpression, while 321 genes were differentially expressed (139 downregulated and 182 upregulated) in response to GGH inhibition (Fig. 2b). As a result of the classification according to function using IPA, genes involved in cellular movement, cell death, and carbohydrate metabolism were differentially expressed in the GGH-overexpressed HCT116 cells, while genes associated with cell death, cell cycle, and cellular movement were identified in the HCT116 cells in which GGH is inhibited (Supplement 6).

\section{Genes differentially expressed in the GGH-modulated MDA-MB-435 cells}

In the MDA-MB-435 cell line, we identified 1,383 genes that were differentially expressed (628 downregulated and 755 upregulated) in response to GGH overexpression, while 859 genes were differentially expressed (402 downregulated and 457 upregulated) in response to GGH inhibition (Fig. 2b). Genes with functions relating to cellto-cell signaling and interaction, cellular movement, and cell death were identified in response to GGH overexpression, while genes associated with cell death, cellular development, and cellular growth and proliferation were differentially expressed in response to GGH inhibition (Supplement 6).

\section{Genes differentially expressed in both the GGH-modulated HCT116 and MDA-MB-435 cells}

We determined genes displaying differential gene expression alterations associated with GGH modulation in both HCT116 and MDA-MB-435 cell lines. We identified nine genes that were downregulated and ten genes that were upregulated in HCT116 and MDA-MB-435 cell lines in response to GGH overexpression (Fig. 2b). We also identified 11 genes that were downregulated and 12 genes that were upregulated in both cell lines in response to GGH inhibition (Fig. 2b). In the GGH-overexpressed HCT116 and MDA-MB-435 cell lines, the commonly downregulated genes were associated with cellular growth and proliferation, cell cycle, gene expression, carbohydrate metabolism, and cellular function and maintenance, whereas the commonly upregulated genes were related to cell cycle, cellular development, molecular transport, small molecule biochemistry, and cellular growth and proliferation (Fig. 2b). In the GGH-inhibited HCT116 and MDAMB-435 cell lines, the major function categories of the commonly downregulated genes included energy production, lipid metabolism, small molecule biochemistry, cell morphology, and cellular development, while those of genes upregulated in common consisted of cell cycle, cell death, cellular development, cellular growth and proliferation, and cell morphology (Fig. 2b). The list of top networks generated by mapping the focus genes that were commonly differentially expressed in both the GGHmodulated HCT116 and MDA-MB-435 cells is presented in Supplement 6 . The list of genes commonly differentially expressed in both cell lines in response to GGH modulation is presented in Fig. 2b.

Integrated analysis of gene expression and DNA methylation changes

We performed an integrated analysis of differentially methylated and expressed genes in response to GGH modulation in order to identify genes, expression of which was regulated by promoter DNA methylation. We detected 21 and 148 genes whose expression was inversely regulated by promoter DNA methylation changes in the GGHmodulated HCT116 and MDA-MB-435 cells, respectively (Fig. 3; Table 1). There were no common genes for which gene expression alterations were correlative with promoter DNA methylation changes in response to GGH modulation between the two cell lines. The list of genes with altered promoter DNA methylation and expression in the GGHmodulated HCT116 and MDA-MB-435 cell lines is presented in Supplement 7.

In HCT116 cells that overexpressed GGH, FGFBPI (fibroblast growth factor binding protein 1), a gene involved in cellular growth and proliferation, displayed promoter DNA hypomethylation and increased gene expression (Supplement 7). In the GGH-inhibited HCT116 cells, epigenetically silenced genes were involved in cellto-cell signaling and interaction, cellular development, cellular growth and proliferation, gene expression, and lipid metabolism, while hypomethylated and upregulated genes were associated with lipid metabolism, small molecule biochemistry, carbohydrate metabolism, cellular movement, and drug metabolism (Table 1).

In the MDA-MB-435 cells that overexpressed GGH, downregulated genes with promoter $\mathrm{CpG}$ hypermethylation were associated with cell signaling, cellular assembly and organization, cellular movement, drug metabolism, and lipid metabolism, while hypomethylated and upregulated genes were involved in cellular assembly and organization, cell-to-cell signaling and interaction, cellular growth and 

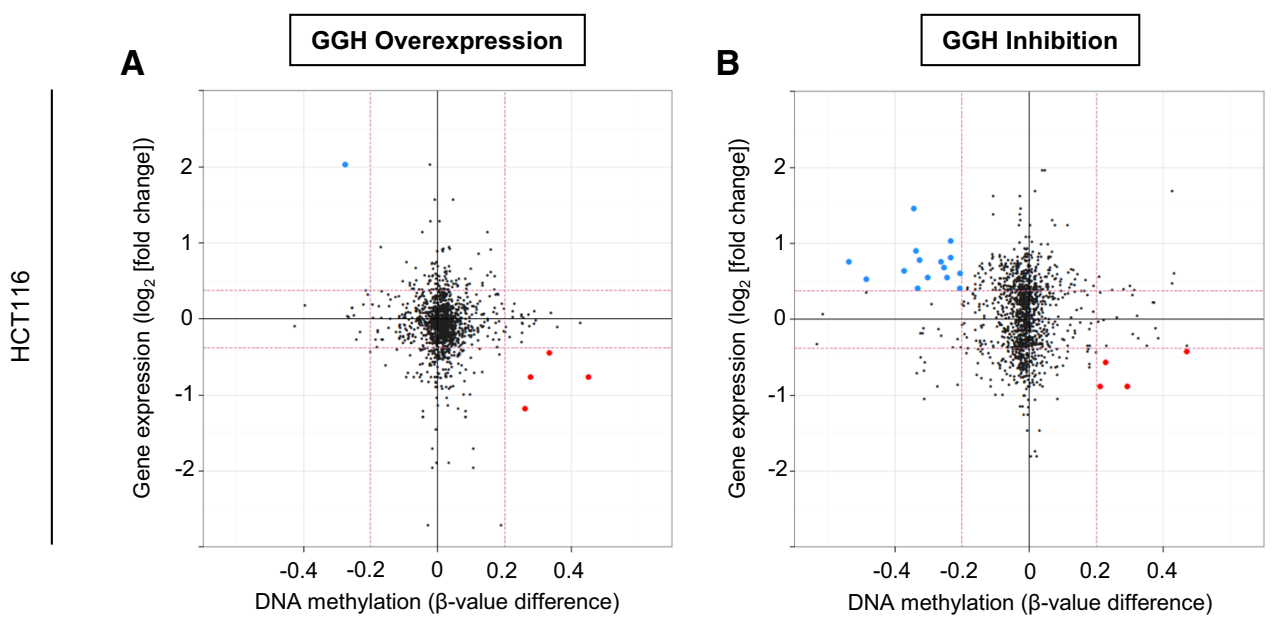

C

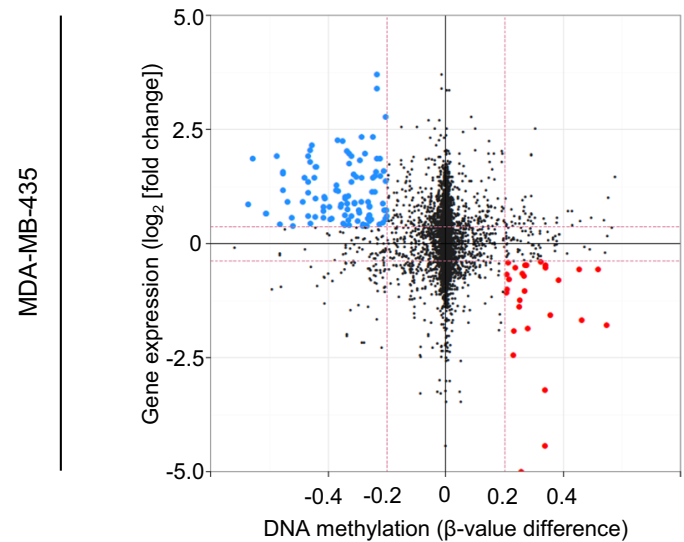

D

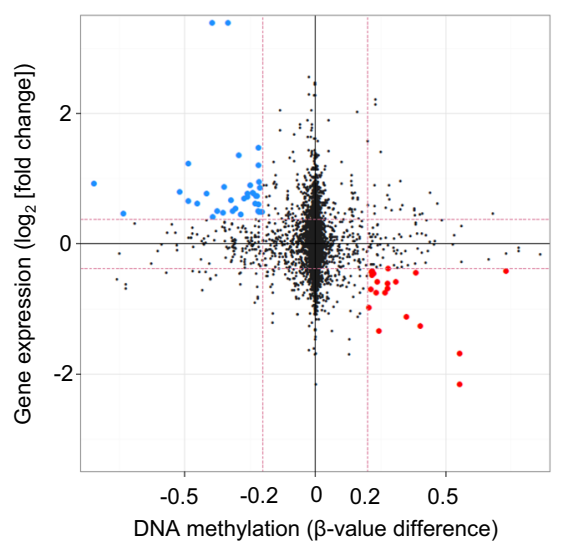

Fig. 3 Integrated analysis of gene expression and promoter DNA methylation changes in the GGH-modulated HCT116 and MDA-MB435 cells. In HCT116 colon cancer cells, we identified 5 (a) and 16 genes (b) for which gene expression was inversely regulated by $\mathrm{CpG}$ promoter DNA methylation changes in response to GGH overexpression and inhibition, respectively. In MDA-MB-435 breast cancer cells, we identified 101 (c) and 47 genes (d) for which gene expression was inversely regulated by $\mathrm{CpG}$ promoter DNA methylation changes in response to GGH overexpression and inhibition,

proliferation, cellular development, and cell death (Table 1). In the MDA-MB-435 cells in which GGH is inhibited, hypermethylated and downregulated genes were involved in cell morphology, cellular development, gene expression, cellular assembly and organization, and cell-tocell signaling and interaction, while hypomethylated and upregulated genes were associated with cell morphology, cell cycle, cellular growth and proliferation, cellular development, and cellular movement (Table 1). Cellular growth and proliferation was the common function of hypomethylated and upregulated genes in both the GGHoverexpressed HCT116 and MDA-MB-435 cells. In both cell lines with GGH inhibition, cell-to-cell signaling and interaction, cellular development, and gene expression were the common functions associated with hypermethylated and downregulated genes, while cellular movement respectively. The $\beta$-value difference and $\log _{2}$-transformed gene expression value difference between Sense and Control-S and between siRNA and Control-si are plotted on $x$ - and $y$-axes, respectively. Red data points highlight those genes that are hypermethylated with $\beta$-value difference $>0.2$ and show $<-1.3$ fold change in their expression levels, while blue data points indicate those genes that are hypomethylated with $\beta$-value difference $<-0.2$ and show $>1.3$ fold change in their expression levels

was the common function associated with hypomethylated and upregulated genes (Table 1).

\section{Validation of gene expression by qRT-PCR}

We performed qRT-PCR to validate the gene expression results of selected genes that were inversely regulated by promoter DNA methylation changes. We selected genes that were associated with a great magnitude of fold change in gene expression on microarray analysis and possessed relevant biological function of interest including cancer, cell cycle, proliferation, and apoptosis. As presented in Supplement 8, although the magnitude of change was different, the direction of change in gene expression in response to GGH modulation was consistent between Illumina gene expression arrays and qRT-PCR analyses in 
Table 1 Number of genes and the top molecular and cellular functions associated with genes with altered expression and promoter DNA methylation in the GGH-modulated HCT116 and MDA-MB-435 cells

\begin{tabular}{|c|c|c|c|c|}
\hline \multirow[t]{2}{*}{ Cell line } & \multirow[t]{2}{*}{ GGH modulation } & \multicolumn{2}{|l|}{ No. of genes } & \multirow[t]{2}{*}{ Top function } \\
\hline & & $\begin{array}{l}\text { Hypermethylated and } \\
\text { downregulated }\end{array}$ & Downregulated & \\
\hline \multirow[t]{2}{*}{ HCT116 } & Overexpression & 4 & 91 & N/A \\
\hline & Inhibition & 3 & 139 & $\begin{array}{l}\text { Cell-to-cell signaling and interaction, cellular development, } \\
\text { cellular growth and proliferation, gene expression, lipid } \\
\text { metabolism }\end{array}$ \\
\hline \multirow[t]{3}{*}{ MDA-MB-435 } & Overexpression & 26 & 628 & $\begin{array}{l}\text { Cell signaling, cellular assembly and organization, cellular } \\
\text { movement, drug metabolism, lipid metabolism }\end{array}$ \\
\hline & Inhibition & 17 & 402 & $\begin{array}{l}\text { Cell morphology, cellular development, gene expression, } \\
\text { cellular assembly and organization, cell-to-cell signaling and } \\
\text { interaction }\end{array}$ \\
\hline & & $\begin{array}{l}\text { Hypomethylated and } \\
\text { upregulated }\end{array}$ & Upregulated & \\
\hline \multirow[t]{2}{*}{ HCT116 } & Overexpression & 1 & 61 & Cellular growth and proliferation \\
\hline & Inhibition & 13 & 182 & $\begin{array}{l}\text { Lipid metabolism, small molecule biochemistry, carbohydrate } \\
\text { metabolism, cellular movement, drug metabolism }\end{array}$ \\
\hline \multirow[t]{2}{*}{ MDA-MB-435 } & Overexpression & 75 & 755 & $\begin{array}{l}\text { Cellular assembly and organization, cell-to-cell signaling and } \\
\text { interaction, cellular growth and proliferation, cellular } \\
\text { development, cell death }\end{array}$ \\
\hline & Inhibition & 30 & 457 & $\begin{array}{l}\text { Cell morphology, cell cycle, cellular growth and proliferation, } \\
\text { cellular development, cellular movement }\end{array}$ \\
\hline
\end{tabular}

N/A not available

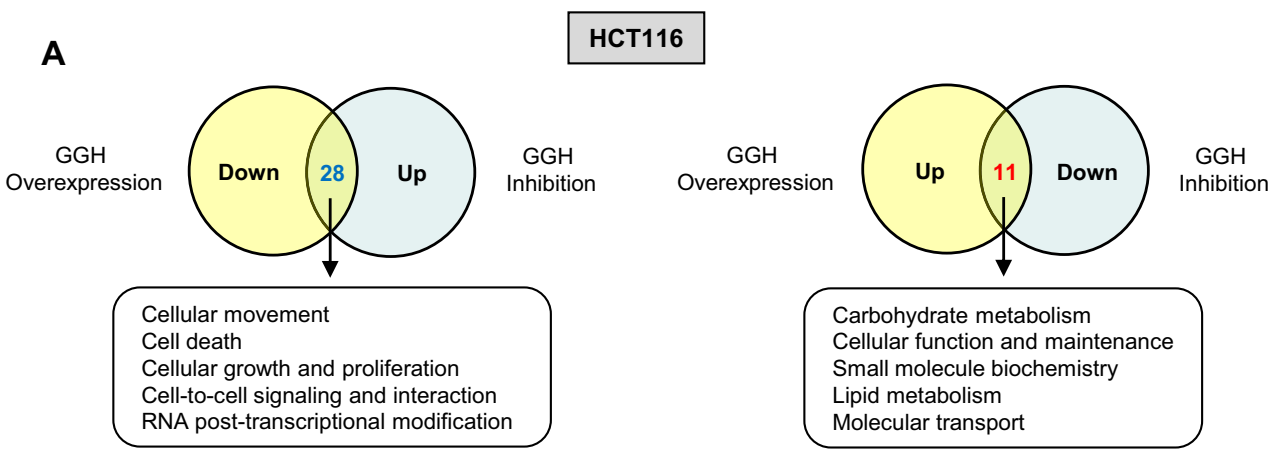

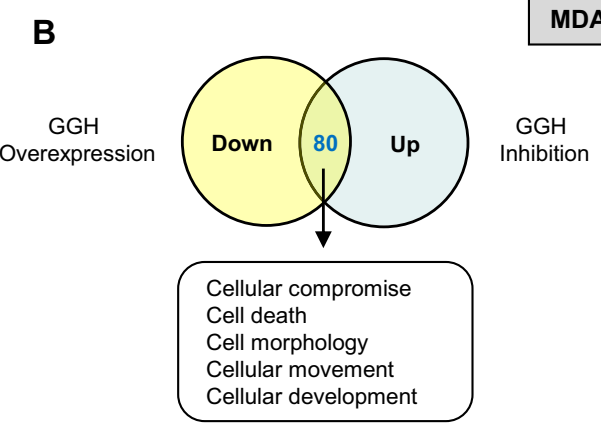

Fig. 4 Number of genes and the top molecular and cellular functions associated with the GGH-specific gene expression. We identified genes differentially expressed in the opposite direction between GGH overexpression and inhibition to investigate genes associated with the GGH-specific altered expression in the GGH-modulated HCT116 and MDA-MB-435 cell lines. Twenty-eight (a) and 80 genes (b) that were

\section{MDA-MB-435}

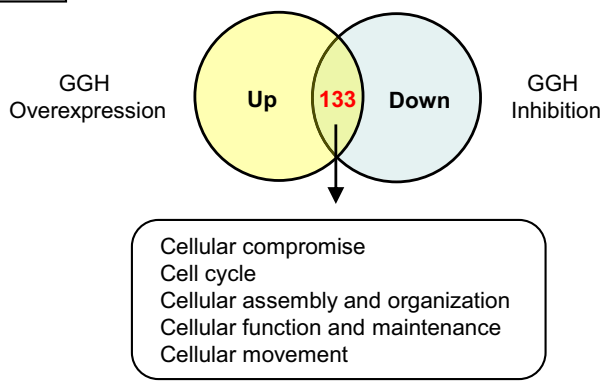

downregulated in response to GGH overexpression and upregulated in response to GGH inhibition were identified in HCT116 and MDAMB-435 cell lines, respectively. We identified that 11 (a) and 133 genes (b) were upregulated in response to GGH overexpression and downregulated associated with GGH inhibition in HCT116 and MDA-MB-435 cell lines, respectively 
Table 2 List of the top genes associated with the GGH-specific altered expression in the GGH-modulated HCT116 colon cancer cells

\begin{tabular}{llll}
\hline Gene symbol & Fold change (vs. control) & Description & Accession \\
\cline { 2 - 3 } & $\begin{array}{lll}\text { GGH } \\
\text { overexpression }\end{array}$ & $\begin{array}{l}\text { GGH } \\
\text { inhibition }\end{array}$ & \\
&
\end{tabular}

Downregulated in GGH overexpression and upregulated in GGH inhibition

\begin{tabular}{|c|c|c|c|c|}
\hline POLE4 & -6.53 & 1.59 & Polymerase (DNA-directed), epsilon 4 (p12 subunit) & NM_019896.2 \\
\hline PVRL3* & -3.86 & 1.41 & Poliovirus receptor-related 3 & NM_015480.1 \\
\hline TNFRSF6B $*$ & -2.61 & 2.49 & Tumor necrosis factor receptor superfamily, member $6 \mathrm{~b}$, decoy & NM_032945.2 \\
\hline PDE4B & -1.77 & 3.24 & $\begin{array}{l}\text { Phosphodiesterase 4B, cAMP-specific (phosphodiesterase E4 dunce } \\
\text { homolog, Drosophila) }\end{array}$ & NM_002600.3 \\
\hline TRIM33 & -1.69 & 1.33 & Tripartite motif-containing 33 & NM_015906.3 \\
\hline PYGL & -1.68 & 1.37 & Phosphorylase, glycogen, liver & NM_002863.3 \\
\hline ALG6 & -1.59 & 1.66 & $\begin{array}{l}\text { Asparagine-linked glycosylation } 6 \text { homolog (S. cerevisiae, alpha-1,3- } \\
\text { glucosyltransferase) }\end{array}$ & NM_013339.2 \\
\hline MTAP & -1.59 & 1.36 & Methylthioadenosine phosphorylase & NM_002451.3 \\
\hline MCOLN2 & -1.54 & 1.51 & Mucolipin 2 & NM_153259.2 \\
\hline SACS & -1.52 & 1.52 & Spastic ataxia of Charlevoix-Saguenay (sacsin) & NM_014363.3 \\
\hline \multicolumn{5}{|c|}{ Upregulated in GGH overexpression and downregulated in GGH inhibition } \\
\hline ANXA10 & 1.62 & -6.85 & Annexin A10 & NM_007193.3 \\
\hline TACSTD2 & 1.37 & -2.38 & Tumor-associated calcium signal transducer 2 & NM_002353.1 \\
\hline TMEM200A & 1.67 & -1.89 & Transmembrane protein $200 \mathrm{~A}$ & NM_052913.2 \\
\hline UPP1 & 1.90 & -1.79 & Uridine phosphorylase 1 & NM_003364.2 \\
\hline PBX1 & 1.68 & -1.73 & Pre-B-cell leukemia homeobox 1 & NM_002585.1 \\
\hline PHF19 & 1.37 & -1.62 & PHD finger protein 19 & NM_001009936.1 \\
\hline RERG & 2.97 & -1.49 & RAS-like, estrogen-regulated, growth inhibitor & NM_032918.1 \\
\hline IRS1 & 1.38 & -1.47 & Insulin receptor substrate 1 & NM_005544.1 \\
\hline PPARG & 1.37 & -1.39 & Peroxisome proliferator-activated receptor gamma & NM_015869.4 \\
\hline RRP7A & 1.32 & -1.36 & $\begin{array}{l}\text { Ribosomal RNA processing } 7 \text { homolog A (S. cerevisiae) (RRP7A), } \\
\text { mRNA }\end{array}$ & NM_015703.3 \\
\hline
\end{tabular}

* A given gene is represented in the microarray set with multiple identifiers

both cell lines $(P<0.05)$, thereby validating the microarray data.

GGH-specific gene expression analysis

To investigate genes whose altered expression might be GGH modulation-specific, we identified genes differentially expressed in the opposite direction between GGH overexpression and inhibition (Supplement 9). In the HCT116 cell line, 28 genes that were downregulated in response to GGH overexpression and upregulated in response to GGH inhibition were associated with cellular movement, cell death, cellular growth and proliferation, cell-to-cell signaling and interaction, and RNA post-transcriptional modification (Fig. 4a). Eleven genes were upregulated in response to GGH overexpression and downregulated in response to GGH inhibition in HCT116 cells, and these genes were involved in carbohydrate metabolism, cellular function and maintenance, small molecule biochemistry, lipid metabolism, and molecular transport (Fig. 4a). The list of the top genes associated with the GGH-specific altered expression in the GGH-modulated HCT116 cells is presented in Table 2. The list of top networks generated by mapping the focus genes associated with the GGH-specific altered expression in the GGHmodulated HCT116 cells is presented in Supplement 10.

In the MDA-MB-435 cell line, 80 genes were downregulated in response to GGH overexpression and upregulated in response to GGH inhibition, and these genes were involved in cellular compromise, cell death, cell morphology, cellular movement, and cellular development (Fig. 4b). One hundred and thirty-three genes that were upregulated in response to $\mathrm{GGH}$ overexpression and downregulated in response to GGH inhibition were associated with cellular compromise, cell cycle, cellular assembly and organization, cellular function and maintenance, and cellular movement in MDA-MB-435 cells (Fig. 4b). The list of the top genes associated with the GGH-specific altered expression in the GGH-modulated MDA-MB-435 cells is presented in Table 3. The list of top 
Table 3 List of the top genes associated with the GGH-specific altered expression in the GGH-modulated MDA-MB-435 breast cancer cells

\begin{tabular}{llll}
\hline $\begin{array}{l}\text { Gene } \\
\text { symbol }\end{array}$ & Fold change (vs. control) & Description & Accession \\
\cline { 2 - 3 } & $\begin{array}{lll}\text { GGH } \\
\text { overexpression }\end{array}$ & $\begin{array}{l}\text { GGH } \\
\text { inhibition }\end{array}$ & \\
\hline
\end{tabular}

Downregulated in GGH overexpression and upregulated in GGH inhibition

\begin{tabular}{|c|c|c|c|c|}
\hline SPP1* & -4.51 & 5.88 & Secreted phosphoprotein 1 & NM_001040058.1 \\
\hline PRSS7* & -1.94 & 4.66 & Protease, serine, 7 (enterokinase) & NM_002772.1 \\
\hline TYR & $-31.95^{\S}$ & 4.07 & Tyrosinase (oculocutaneous albinism IA) & NM_000372.4 \\
\hline CYB5R2 & -1.34 & 3.05 & Cytochrome b5 reductase 2 & NM_016229.3 \\
\hline BCHE* & -4.82 & $2.31^{\S}$ & Butyrylcholinesterase & NM_000055.2 \\
\hline $\mathrm{ADM}$ & -2.63 & 2.31 & Adrenomedullin & NM_001124.1 \\
\hline TMEM166 & -3.05 & 2.07 & Transmembrane protein 166 & NM_032181.1 \\
\hline ORC5L & -1.35 & 2.07 & Origin recognition complex, subunit 5-like (yeast) & NM_002553.2 \\
\hline PNLIPRP3 & -1.34 & 2.05 & Pancreatic lipase-related protein 3 & NM_001011709.1 \\
\hline DYNC1I1 & -5.83 & 2.03 & Dynein, cytoplasmic 1 , intermediate chain 1 & NM_004411.3 \\
\hline \multicolumn{5}{|c|}{ Upregulated in GGH overexpression and downregulated in GGH inhibition } \\
\hline CTHRC1* & 1.77 & $-4.44^{\S}$ & Collagen triple helix repeat containing 1 & NM_138455.2 \\
\hline NNMT & $4.80^{\S}$ & -3.24 & Nicotinamide $N$-methyltransferase & NM_006169.2 \\
\hline HLA-DOA & 1.44 & -3.09 & Major histocompatibility complex, class II, DO alpha & NM_002119.3 \\
\hline FSCN1 & 3.31 & -3.03 & Fascin homolog 1, actin-bundling protein (Strongylocentrotus purpuratus) & NM_003088.2 \\
\hline CDC42EP5 & $3.76^{\S}$ & $-2.53^{\S}$ & CDC42 effector protein (Rho GTPase binding) 5 & NM_145057.2 \\
\hline CHN1 & $2.79^{\S}$ & -2.30 & Chimerin (chimaerin) 1 & NM_001025201.1 \\
\hline SLC2A3 & 1.94 & -2.24 & Solute carrier family 2 (facilitated glucose transporter), member 3 & NM_006931.1 \\
\hline $\begin{array}{l}\text { HLA- } \\
\text { DRB6 }\end{array}$ & 2.91 & -2.20 & Major histocompatibility complex, class II, DR beta 6 (pseudogene) & NR_001298.1 \\
\hline $\begin{array}{l}\text { HLA- } \\
\text { DQA1 }\end{array}$ & 6.26 & -2.19 & $\begin{array}{l}\text { PREDICTED: major histocompatibility complex, class II, DQ alpha } 1 \text {, } \\
\text { transcript variant } 10\end{array}$ & XM_936128.2 \\
\hline PHF21A & 1.75 & -2.11 & PHD finger protein $21 \mathrm{~A}$ & NM_016621.2 \\
\hline C21orf34 & 1.39 & -2.11 & Chromosome 21 open reading frame 34 & NM_001005734.1 \\
\hline S100A4* & $13.13^{\S}$ & -2.10 & S100 calcium-binding protein A4 & NM_019554.2 \\
\hline
\end{tabular}

* A given gene is represented in the microarray set with multiple identifiers; ${ }^{\S}$ Expression of gene was regulated by DNA methylation

networks generated by mapping the focus genes associated with the GGH-specific altered expression in the GGHmodulated MDA-MB-435 cells is presented in Supplement 10 .

We identified several genes with GGH-specific altered expression changes which were regulated by promoter DNA methylation. TYR was one of the most downregulated (fold change -31.95$)$ and hypermethylated ( $\beta$-value difference 0.26 ) genes in the GGH-overexpressed MDA-MB435 cells, and it was upregulated (fold change 4.07) in the GGH-inhibited MDA-MB-435 cells (Table 3; Supplement 7). $T Y R$ encodes tyrosinase, a melanosomal enzyme that catalyzes the rate-limiting steps of melanin biosynthesis (Spritz et al. 2003). BCHE, which encodes butyrylcholinesterase, was associated with upregulation and hypomethylation in the GGH-inhibited MDA-MB-435 cells, and it was downregulated in response to GGH overexpression in the same cell line (Table 3; Supplement 7). Furthermore, in the GGH-overexpressed MDA-MB-435 cells, we identified upregulated and hypomethylated genes that were downregulated in the GGH-inhibited MDA-MB-435 cells including S100A4 and NNMT (Table 3; Supplement 7). In MDA-MB-435 cells, CDC42EP5, CDC42 effector protein (Rho GTPase binding) 5, was hypomethylated ( $\beta$-value difference -0.58) and upregulated (fold change 3.76 ) in GGH overexpression, while it was hypermethylated ( $\beta$-value difference 0.24 ) and downregulated (fold change -2.53) in GGH inhibition (Table 3; Supplement 7). No common genes were identified in both HCT116 and MDA-MB-435 cell lines.

\section{Discussion}

In the present study, we investigated the effects of GGH modulation on global and gene-specific DNA methylation and gene expression using a recently developed in vitro model of GGH overexpression and inhibition in HCT116 
and MDA-MB-435 cells with predictable functional consequences (Kim et al. 2013). Generally, most of the observed functional consequences of GGH overexpression and inhibition in this model were consistent with the known biological function of GGH and provided an appropriate in vitro model to test the effect of $\mathrm{GGH}$ modulation on DNA methylation (Kim et al. 2013).

We first investigated whether the changes in total intracellular folate concentrations and in the content of polyglutamylated folate cofactors resulting from $\mathrm{GGH}$ modulation would affect global DNA methylation and DNMT activity in HCT116 colon and MDA-MB-435 breast cancer cells. In both HCT116 and MDA-MB-435 cells, GGH overexpression was associated with decreased global DNA methylation and DNMT activity, which is likely related to the lower total intracellular folate concentrations and lower content of long-chain folylpolyglutamates in response to $\mathrm{GGH}$ overexpression (Kim et al. 2013). In contrast, GGH inhibition demonstrated increased global DNA methylation and DNMT activity. This finding is likely accounted for by the higher total intracellular folate concentrations and higher content of long-chain folylpolyglutamates in response to $\mathrm{GGH}$ inhibition (Iacopetta et al. 2008; Kim et al. 2013). Indeed, low GGH expression was associated with $\mathrm{CpG}$ island methylator phenotype (CIMP+) colorectal cancer, a subgroup of colorectal cancer with concurrent hypermethylation of a large number of $\mathrm{CpG}$ islands mostly of tumor suppressor genes (Toyota et al. 1999), and increased folate intermediates in colorectal cancer (Kawakami et al. 2008). These observations suggest that low GGH expression may be linked to increased promoter methylation in CIMP+ tumors by causing elevation of folate concentrations and that aberrant GGH in the folate metabolic pathway may be involved in CIMP+ colorectal cancer carcinogenesis (Kawakami et al. 2008). Collectively, expression of GGH appears to be one of the important factors in determining DNA methylation status, probably through an effect on folate metabolism (Kawakami et al. 2003, 2008).

Epigenomic and gene expression analyses data suggest that GGH modulation influenced promoter $\mathrm{CpG}$ DNA methylation and gene expression involved in important biological pathways. MDA-MB-435 cells revealed more promoter $\mathrm{CpG}$ methylation and gene expression alterations in response to GGH modulation compared with HCT116 cells. GGH inhibition demonstrated greater promoter $\mathrm{CpG}$ methylation changes compared with GGH overexpression in both cell lines. In both HCT116 and MDA-MB-435 cells, differentially methylated genes associated with cell cycle and cellular assembly and organization were affected by GGH overexpression, while genes involved in small molecule biochemistry and lipid metabolism were differentially methylated in response to GGH inhibition. In both cell lines, expression of genes involved in cellular growth and proliferation and cell cycle were affected by GGH overexpression, whereas genes related to cell morphology and cellular development were differentially expressed in response to GGH inhibition. However, some of the pathways affected by GGH modulation might be indirect consequences of changes in total folate content and polyglutamylated folate cofactors or of changes in cell proliferation or morphology. Overall, only a small number of genes were associated with the inverse relationship between promoter DNA methylation and gene expression in response to GGH modulation. This observation is similar to reports from other studies (Houshdaran et al. 2010; Pike et al. 2008). It appears that the genetic, other epigenetic mechanisms such as histone modifications, chromatin remodeling, and RNA interference, and/or changes in activities of other genes for which expression was directly influenced by promoter DNA methylation are likely responsible for the observed gene expression changes in response to GGH modulation in the present study.

In MDA-MB-435 cells, we identified genes that were upregulated and hypomethylated in response to $\mathrm{GGH}$ overexpression and downregulated in response to $\mathrm{GGH}$ inhibition including S100A4 and NNMT. S100A4 encodes a member of the S100 family of calcium-binding proteins. S100 family members have a wide range of intracellular functions, including the regulation of homeostasis, protein phosphorylation, cytoskeletal rearrangements, and transcriptional activity, and extracellular functions such as the regulation of cell proliferation and activation, apoptosis, and chemotaxis (Garrett et al. 2006; Santamaria-Kisiel et al. 2006). NNMT encodes nicotinamide $N$-methyltransferase, an enzyme that catabolizes nicotinamide and other pyridine compounds in a reaction that uses the methyl group generated during the conversion of SAM to $S$-adenosylhomocysteine, involved in the biotransformation of many drugs and xenobiotic compounds (Aksoy et al. 1994). A recent study found that downregulation of NNMT inhibited proliferation in KB cancer cells, suggesting NNMT might be a target for therapeutics and could alter the efficacy of standard chemotherapeutic drugs (Pozzi et al. 2011). Furthermore, in MDA-MB-435 cells, CDC42EP5 was hypomethylated and upregulated in GGH overexpression, while it was hypermethylated and downregulated in GGH inhibition. CDC42EP5, CDC42 effector protein 5, is involved in the organization of the actin cytoskeleton and acts downstream of CDC42 to induce actin filament assembly leading to cell shape changes (Hirsch et al. 2001).

In MDA-MB-435 cells overexpressing GGH, differential expression of several genes involved in folate biosynthesis and one-carbon metabolism including DPYD, $A B C C 5$, and $S L C 25 A 32$ is in line with the GGH 
modulation-induced changes in cellular folate homeostasis and drug efficacy reported in the previous study (Kim et al. 2013). DPYD encodes dihydropyrimidine dehydrogenase that is the rate-limiting enzyme involved in 5-fluorouracil (5FU) metabolism and a major determinant of 5FU efficacy (Oguri et al. 2005; Yoshinare et al. 2003). DPYD overexpression in cancer cell lines is associated with 5FU resistance (Takebe et al. 2001), and high DPYD mRNA expression in colorectal tumors has been shown to correlate with resistance to 5FU (Salonga et al. 2000). In contrast, in CIMP+ colorectal cancers, promoter methylation-induced silencing of DPYD was associated with an enhanced response to 5FU (Iacopetta et al. 2008). Thus, it appears that the observed upregulation of $D P Y D$ in the GGHoverexpressed MDA-MB-435 cells might be associated with 5FU resistance. Indeed, we have shown that $\mathrm{GGH}$ overexpression decreased 5FU efficacy in MDA-MB-435 cells (Kim et al. 2013).

Multidrug-resistance-associated protein 5 (MRP5) encoded by the $A B C C 5$ gene is associated with resistance to antifolates and 5FU. MRP5 can efflux mono- and diglutamate forms of methotrexate (MTX) and transport 5-fluoro-2-deoxyuridine-5-monophosphate, a metabolite of 5FU (Assaraf 2007; Hooijberg et al. 2006; Pratt et al. 2005; Wielinga et al. 2005). MRPs contribute to drug resistance or increase drug efficacy depending on polyglutamylation of antifolates and intracellular folate concentrations (Assaraf 2006). In addition, the SLC25A32 gene encodes a folate transporter that shuttles folate from the cytoplasm into the mitochondria (Titus and Moran 2000). A reduced, monoglutamylated form of cytoplasmic folate (probably tetrahydrofolate or 5-formyltetrahydrofolate) is transported to the mitochondria by the mitochondrial folate transporter, followed by the mitochondrial FPGS-induced polyglutamylation resulting in mitochondrial folate accumulation (Chen et al. 1996). Taken together, downregulation of $A B C C 5$ and SLC25A32 associated with GGH overexpression supports the role of MRP5 and the mitochondrial folate transporter in the modulation of the intracellular folate levels as well as cellular folate homeostasis since we have previously found that GGH overexpression decreased total intracellular folate concentrations in MDA-MB-435 cells (Kim et al. 2013).

In addition, $C D K 2$ encodes cyclin-dependent kinase 2 that maintains a balance of $\mathrm{S}$-phase regulatory proteins and thereby coordinates subsequent p53-independent G2/M checkpoint activation (Chung and Bunz 2010). CDK2 expression was downregulated in the 5FU resistant cell lines, suggesting that decreased CDK2 activity may delay the transition of resistant cells from G1 into S-phase (Guo et al. 2008; Wang et al. 2004). Delayed S-phase entry and/ or reduced $\mathrm{S}$-phase traverse may provide resistant cells with enough time to repair 5FU-induced damage before progressing to G2-M phase. Thus, 5FU resistance may be, at least partially, reversed by specific targeting of the G1-S checkpoint arrest in the resistant cells (Wang et al. 2004). Accordingly, downregulation of $C D K 2$ in the GGH-overexpressed MDA-MB-435 cells is likely to be associated with decreased 5FU efficacy (Kim et al. 2013). Restoration of the G1 checkpoint by targeting CDK2 is currently one of the major strategies for anticancer drug development (Malumbres and Barbacid 2001).

GGH, along with a tightly coupled counter-regulation by FPGS, plays an important role in maintenance of optimal intracellular folate concentrations and polyglutamylated forms for critical folate-dependent one-carbon transfer reactions involved in nucleotide biosynthesis and biological methylation reactions (Shane 2010). Intracellular folate depletion/excess as well as altered folylpolyglutamate distribution leads to perturbations in the nucleotide synthesis and biological methylation pathways (Shane 1989, 2010). Indeed, folate deficiency has been linked to the development of anemia, coronary heart disease, neural tube defects and other congenital disorders, cognitive impairments, and cancers, primarily through aberrant DNA synthesis, stability, integrity, repair, and methylation (Kim 2005, 2007). Furthermore, folate excess has been shown to exert adverse health effects, including tumor promotion and metabolic syndrome, likely via aberrant nucleotide biosynthesis and biological methylation reactions (Kim 2007; Yajnik et al. 2008). Given the critical role of GGH in intracellular folate homeostasis, dysregulation of GGH and consequent perturbations in intracellular folate concentrations and folylpolyglutamate distribution will likely contribute to the development and progression of certain human diseases that are linked to aberrant folate and onecarbon metabolism.

The role of GGH in human health and disease, however, has not yet been clearly demonstrated. An emerging body of studies has reported several single nucleotide polymorphisms (SNPs) in GGH significantly influence GGH expression and activity (Chave et al. 2003; Cheng et al. 2004; Dervieux et al. 2004; DeVos et al. 2008). It has been recently reported that some GGH SNPs are associated with an increased risk of cancer as well as a decreased risk of cardiovascular disease (DeVos et al. 2008; Organista-Nava et al. 2010; Wernimont et al. 2012). In addition to SNPs, $\mathrm{CpG}$ methylation in the human GGH promoter region has been shown to significantly alter GGH expression and activity (Cheng et al. 2006). Our data demonstrate that GGH modulation associated with significant changes in intracellular folate concentrations and folylpolyglutamate distribution can lead to altered expression and CpG DNA methylation of genes involved in important biological pathways that might contribute to the development and progression of diseases that are linked to aberrant 
intracellular folate and one-carbon metabolism. Whether or not recently identified and characterized GGH SNPs or epigenetic variants with functionally significant effects on GGH expression and activity may be associated with altered expression and $\mathrm{CpG}$ methylation of genes involved in important biological pathways needs to be confirmed in future clinical and epidemiologic studies. This is an important issue as individuals with certain GGH SNPs may be at risk of developing diseases that are linked to aberrant intracellular folate and one-carbon metabolism and specific forms and amount of folate or folic acid may be required to nullify the risk.

The role of GGH in cancer risk, progression, and treatment has been under intense investigation. Similar to folates, intracellular homeostasis of antifolates such as MTX are regulated by GGH (Cheng et al. 2004; Panetta et al. 2002; Rhee et al. 1999; Yao et al. 1995). Alterations in concentrations and polyglutamylation of both folate and antifolates resulting from GGH modulation can significantly influence cancer risk, progression and treatment response to antifolates (Kim et al. 2013). In addition to the previously mentioned association of GGH expression with CIMP+ colorectal cancer (Kawakami et al. 2008), GGH expression may be a prognostic indicator of cancer. For example, a recent study has reported that high GGH protein level is associated with poor prognosis and unfavorable clinical outcomes in patients with invasive breast cancer (Shubbar et al. 2013). Furthermore, clinical studies investigating the role of GGH in modulating chemosensitivity to $5 \mathrm{FU}$, the cornerstone of colorectal and breast cancer chemotherapy, and antifolates have begun to emerge. Low GGH expression was reported to correlate with an enhanced response to 5FU-based chemotherapy in patients with metastatic colorectal cancer (Nakajima et al. 2008). In patients with advanced pancreatic cancer treated with an oral fluoropyrimidine derivative, $\mathrm{S}-1$, low GGH expression was associated with improved overall survival (Nakamura et al. 2011). In acute myelogenous leukemia, it was found that high GGH activity may play a role in inherent drug resistance to MTX (Rots et al. 1999). High GGH expression was shown to be associated with a higher risk of developing advanced toxicity to pemetrexed, a multi-targeted antifolate, in patients with advanced breast cancer (Llombart-Cussac et al. 2007). Furthermore, several recently identified and characterized functionally significant genetic and epigenetic polymorphisms of GGH have been reported to predict response to and toxicity of antifolate-based treatment in patients with several cancers (Cheng et al. 2004; Kim et al. 2008; Koomdee et al. 2012; Silva et al. 2013; Smit et al. 2012; Wang et al. 2014) and inflammatory arthritis (Dervieux et al. 2004; Hayashi et al. 2009; Jekic et al. 2013; Owen et al. 2012; van der Straaten et al. 2007; Yanagimachi et al. 2011). Our data herein provide evidence that GGH modulation significantly influences expression and CpG DNA methylation of genes involved in important biological pathways that might account for the observed effects of GGH modulation on cancer risk, prognosis, and treatment response. Furthermore, our data provide a framework for future studies aimed at interrogating specific biological pathways associated with GGH modulation and at exploring upstream and downstream targets of GGH modulation.

In conclusion, our results suggest that the GGH modulation-induced changes in total intracellular folate concentrations and content of long-chain folylpolyglutamates significantly influenced global DNA methylation and DNMT activity as well as promoter DNA methylation and gene expression. We demonstrated that GGH overexpression was associated with decreased global DNA methylation and DNMT activity, while GGH inhibition showed increased global DNA methylation and DNMT activity. Furthermore, we showed that GGH modulation was associated with differential promoter DNA methylation and gene expression involved in important biological pathways and some of the observed altered gene expression appeared to be regulated by promoter DNA methylation changes. In the GGH-overexpressed MDA-MB-435 cells, we identified several differentially expressed genes involved in folate biosynthesis, one-carbon pool by folate, and cell cycle, which might in part have contributed to the observed decreased total intracellular folate concentrations and 5FU efficacy in response to GGH overexpression. The potential role of GGH modulation in DNA methylation and its associated downstream functional effects needs further exploration.

Acknowledgments Funding was provided by the Canadian Institutes of Health Research (Grant Number 14126 to YIK).

Conflict of interest The authors declare no conflict of interest.

\section{References}

Aksoy S, Szumlanski CL, Weinshilboum RM (1994) Human liver nicotinamide N-methyltransferase. cDNA cloning, expression, and biochemical characterization. J Biol Chem 269:14835-14840

Assaraf YG (2006) The role of multidrug resistance efflux transporters in antifolate resistance and folate homeostasis. Drug Resist Updat 9:227-246. doi:10.1016/j.drup.2006.09.001

Assaraf YG (2007) Molecular basis of antifolate resistance. Cancer Metastasis Rev 26:153-181. doi:10.1007/s10555-007-9049-z

Bibikova M, Le J, Barnes B, Saedinia-Melnyk S, Zhou L, Shen R, Gunderson KL (2009) Genome-wide DNA methylation profiling using Infinium((R)) assay. Epigenomics 1:177-200. doi:10.2217/ epi.09.14

Campan M, Weisenberger DJ, Trinh B, Laird PW (2009) MethyLight. Methods Mol Biol 507:325-337. doi:10.1007/978-159745-522-0_23 
Chave KJ, Ryan TJ, Chmura SE, Galivan J (2003) Identification of single nucleotide polymorphisms in the human gamma-glutamyl hydrolase gene and characterization of promoter polymorphisms. Gene 319:167-175

Chen L, Qi H, Korenberg J, Garrow TA, Choi YJ, Shane B (1996) Purification and properties of human cytosolic folylpoly-gammaglutamate synthetase and organization, localization, and differential splicing of its gene. J Biol Chem 271:13077-13087

Cheng Q et al (2004) A substrate specific functional polymorphism of human gamma-glutamyl hydrolase alters catalytic activity and methotrexate polyglutamate accumulation in acute lymphoblastic leukaemia cells. Pharmacogenetics 14:557-567

Cheng Q, Cheng C, Crews KR, Ribeiro RC, Pui CH, Relling MV, Evans WE (2006) Epigenetic regulation of human gammaglutamyl hydrolase activity in acute lymphoblastic leukemia cells. Am J Hum Genet 79:264-274. doi:10.1086/505645

Chung JH, Bunz F (2010) Cdk2 is required for p53-independent G2/ M checkpoint control. PLoS Genet 6:e1000863. doi:10.1371/ journal.pgen. 1000863

Dervieux T et al (2004) Contribution of common polymorphisms in reduced folate carrier and gamma-glutamylhydrolase to methotrexate polyglutamate levels in patients with rheumatoid arthritis. Pharmacogenetics 14:733-739

DeVos L et al (2008) Associations between single nucleotide polymorphisms in folate uptake and metabolizing genes with blood folate, homocysteine, and DNA uracil concentrations. Am J Clin Nutr 88:1149-1158

Garrett SC, Varney KM, Weber DJ, Bresnick AR (2006) S100A4, a mediator of metastasis. J Biol Chem 281:677-680. doi:10.1074/ jbc.R500017200

Guo X, Goessl E, Jin G, Collie-Duguid ES, Cassidy J, Wang W, O'Brien V (2008) Cell cycle perturbation and acquired 5-fluorouracil chemoresistance. Anticancer Res 28:9-14

Hayashi H, Fujimaki C, Daimon T, Tsuboi S, Matsuyama T, Itoh K (2009) Genetic polymorphisms in folate pathway enzymes as a possible marker for predicting the outcome of methotrexate therapy in Japanese patients with rheumatoid arthritis. J Clin Pharm Ther 34:355-361

Herman JG, Baylin SB (2003) Gene silencing in cancer in association with promoter hypermethylation. N Engl J Med 349:2042-2054. doi:10.1056/NEJMra023075

Hirsch DS, Pirone DM, Burbelo PD (2001) A new family of Cdc42 effector proteins, CEPs, function in fibroblast and epithelial cell shape changes. J Biol Chem 276:875-883. doi:10.1074/jbc. M007039200

Hooijberg JH, de Vries NA, Kaspers GJ, Pieters R, Jansen G, Peters GJ (2006) Multidrug resistance proteins and folate supplementation: therapeutic implications for antifolates and other classes of drugs in cancer treatment. Cancer Chemother Pharmacol 58:1-12. doi:10.1007/s00280-005-0141-1

Houshdaran S et al (2010) DNA methylation profiles of ovarian epithelial carcinoma tumors and cell lines. PLoS ONE 5:e9359. doi:10.1371/journal.pone.0009359

Iacopetta B, Kawakami K, Watanabe T (2008) Predicting clinical outcome of 5-fluorouracil-based chemotherapy for colon cancer patients: is the $\mathrm{CpG}$ island methylator phenotype the 5-fluorouracil-responsive subgroup? Int J Clin Oncol 13:498-503. doi:10.1007/s10147-008-0854-3

Jekic B et al (2013) Association of the TYMS 3G/3G genotype with poor response and GGH $354 \mathrm{GG}$ genotype with the bone marrow toxicity of the methotrexate in RA patients. Eur J Clin Pharmacol 69:377-383. doi:10.1007/s00228-012-1341-3

Kawakami K, Ruszkiewicz A, Bennett G, Moore J, Watanabe G, Iacopetta B (2003) The folate pool in colorectal cancers is associated with DNA hypermethylation and with a polymorphism in methylenetetrahydrofolate reductase. Clin Cancer Res 9:5860-5865

Kawakami K et al (2008) Low expression of gamma-glutamyl hydrolase mRNA in primary colorectal cancer with the $\mathrm{CpG}$ island methylator phenotype. Br J Cancer 98:1555-1561. doi:10. 1038/sj.bjc.6604346

Kim YI (2004) Folate and DNA methylation: a mechanistic link between folate deficiency and colorectal cancer? Cancer Epidemiol Biomark Prev 13:511-519

Kim YI (2005) Nutritional epigenetics: impact of folate deficiency on DNA methylation and colon cancer susceptibility. J Nutr 135:2703-2709

Kim YI (2007) Folate and colorectal cancer: an evidence-based critical review. Mol Nutr Food Res 51:267-292. doi:10.1002/ mnfr.200600191

Kim K, Kang SB, Chung HH, Kim JW, Park NH, Song YS (2008) XRCC1 Arginine194Tryptophan and GGH-401Cytosine/Thymine polymorphisms are associated with response to platinumbased neoadjuvant chemotherapy in cervical cancer. Gynecol Oncol 111:509-515. doi:10.1016/j.ygyno.2008.08.034

Kim SE et al (2013) Gamma-glutamyl hydrolase modulation and folate influence chemosensitivity of cancer cells to 5-fluorouracil and methotrexate. Br J Cancer 109:2175-2188. doi:10.1038/bjc. 2013.579

Koomdee N, Hongeng S, Apibal S, Pakakasama S (2012) Association between polymorphisms of dihydrofolate reductase and gamma glutamyl hydrolase genes and toxicity of high dose methotrexate in children with acute lymphoblastic leukemia. Asian Pac J Cancer Prev 13:3461-3464

Kulis M, Esteller M (2010) DNA methylation and cancer. Adv Genet 70:27-56. doi:10.1016/B978-0-12-380866-0.60002-2

Laird PW, Zijderveld A, Linders K, Rudnicki MA, Jaenisch R, Berns A (1991) Simplified mammalian DNA isolation procedure. Nucleic Acids Res 19:4293

Li EJR (2000) DNA methylation and methyltransferases. In: Natick EM (ed) DNA alterations in cancer: genetic and epigenetic changes. Eaton Publishing, MA, pp 351-365

Livak KJ, Schmittgen TD (2001) Analysis of relative gene expression data using real-time quantitative PCR and the 2(-Delta Delta C(T)) method. Methods 25:402-408. doi:10.1006/meth.2001.1262

Llombart-Cussac A et al (2007) A randomized, double-blind, phase II study of two doses of pemetrexed as first-line chemotherapy for advanced breast cancer. Clin Cancer Res 13:3652-3659. doi:10. 1158/1078-0432.CCR-06-2377

Ly A, Hoyt L, Crowell J, Kim YI (2012) Folate and DNA methylation. Antioxid Redox Signal 17:302-326. doi:10.1089/ ars.2012.4554

Malumbres M, Barbacid M (2001) To cycle or not to cycle: a critical decision in cancer. Nat Rev Cancer 1:222-231. doi:10.1038/ 35106065

McGuire JJ, Bertino JR (1981) Enzymatic synthesis and function of folylpolyglutamates. Mol Cell Biochem 38:19-48. doi:10.1007/ BF00235686

Moran RG (1999) Roles of folylpoly-gamma-glutamate synthetase in therapeutics with tetrahydrofolate antimetabolites: an overview. Semin Oncol 26:24-32

Nakajima TE et al (2008) Combination of O6-methylguanine-DNA methyltransferase and thymidylate synthase for the prediction of fluoropyrimidine efficacy. Eur J Cancer 44:400-407. doi:10. 1016/j.ejca.2007.11.010

Nakamura A et al (2011) Impact of dihydropyrimidine dehydrogenase and gamma-glutamyl hydrolase on the outcomes of patients treated with gemcitabine or S-1 as adjuvant chemotherapy for advanced pancreatic cancer. Exp Ther Med 2:1097-1103. doi:10.3892/etm.2011.340 
Noushmehr $\mathrm{H}$ et al (2010) Identification of a CpG island methylator phenotype that defines a distinct subgroup of glioma. Cancer Cell 17:510-522. doi:10.1016/j.ccr.2010.03.017

Oguri $\mathrm{T}$ et al (2005) The role of thymidylate synthase and dihydropyrimidine dehydrogenase in resistance to 5-fluorouracil in human lung cancer cells. Lung Cancer 49:345-351. doi:10. 1016/j.lungcan.2005.05.003

Organista-Nava J et al (2010) Polymorphisms of the gamma-glutamyl hydrolase gene and risk of relapse to acute lymphoblastic leukemia in Mexico. Leuk Res 34:728-732. doi:10.1016/j. leukres.2009.11.027

Owen SA, Hider SL, Martin P, Bruce IN, Barton A, Thomson W (2012) Genetic polymorphisms in key methotrexate pathway genes are associated with response to treatment in rheumatoid arthritis patients. Pharmacogenomics J 13:227-234. doi:10.1038/ tpj.2012.7

Panetta JC, Wall A, Pui CH, Relling MV, Evans WE (2002) Methotrexate intracellular disposition in acute lymphoblastic leukemia: a mathematical model of gamma-glutamyl hydrolase activity. Clin Cancer Res 8:2423-2429

Pike BL et al (2008) DNA methylation profiles in diffuse large B-cell lymphoma and their relationship to gene expression status. Leukemia 22:1035-1043. doi:10.1038/leu.2008.18

Pozzi V et al (2011) Inhibiting proliferation in KB cancer cells by RNA interference-mediated knockdown of nicotinamide $\mathrm{N}$-methyltransferase expression. Int J Immunopathol Pharmacol 24:69-77

Pratt S, Shepard RL, Kandasamy RA, Johnston PA, Perry W 3rd, Dantzig AH (2005) The multidrug resistance protein 5 (ABCC5) confers resistance to 5-fluorouracil and transports its monophosphorylated metabolites. Mol Cancer Ther 4:855-863. doi:10. 1158/1535-7163.MCT-04-0291

Rhee MS, Ryan TJ, Galivan J (1999) Glutamyl hydrolase and the multitargeted antifolate LY231514. Cancer Chemother Pharmacol 44:427-432

Rots MG et al (1999) Role of folylpolyglutamate synthetase and folylpolyglutamate hydrolase in methotrexate accumulation and polyglutamylation in childhood leukemia. Blood 93:1677-1683

Salonga D et al (2000) Colorectal tumors responding to 5-fluorouracil have low gene expression levels of dihydropyrimidine dehydrogenase, thymidylate synthase, and thymidine phosphorylase. Clin Cancer Res 6:1322-1327

Santamaria-Kisiel L, Rintala-Dempsey AC, Shaw GS (2006) Calcium-dependent and -independent interactions of the S100 protein family. Biochem J 396:201-214. doi:10.1042/BJ200 60195

Shane B (1989) Folylpolyglutamate synthesis and role in the regulation of one-carbon metabolism. Vitam Horm 45:263-335

Shane B (2010) Folate chemistry and metabolism. In: Bailey LB (ed) Folate in health and disease. CRC Press, Boca Raton, pp 1-24

Shubbar E, Helou K, Kovacs A, Nemes S, Hajizadeh S, Enerback C, Einbeigi Z (2013) High levels of gamma-glutamyl hydrolase $(\mathrm{GGH})$ are associated with poor prognosis and unfavorable clinical outcomes in invasive breast cancer. BMC Cancer 13:47. doi:10.1186/1471-2407-13-47

Silva IH et al (2013) The impact of GGH $-401 \mathrm{C}>\mathrm{T}$ polymorphism on cisplatin-based chemoradiotherapy response and survival in cervical cancer. Gene 512:247-250. doi:10.1016/j.gene.2012.10. 038
Smit EF et al (2012) Biomarker analysis in a phase III study of pemetrexed-carboplatin versus etoposide-carboplatin in chemonaive patients with extensive-stage small-cell lung cancer. Ann Oncol 23:1723-1729. doi:10.1093/annonc/mdr563

Sohn KJ, Croxford R, Yates Z, Lucock M, Kim YI (2004) Effect of the methylenetetrahydrofolate reductase C677T polymorphism on chemosensitivity of colon and breast cancer cells to 5-fluorouracil and methotrexate. J Natl Cancer Inst 96:134-144

Spritz RA, Chiang PW, Oiso N, Alkhateeb A (2003) Human and mouse disorders of pigmentation. Curr Opin Genet Dev 13:284-289

Takebe N, Zhao SC, Ural AU, Johnson MR, Banerjee D, Diasio RB, Bertino JR (2001) Retroviral transduction of human dihydropyrimidine dehydrogenase cDNA confers resistance to 5-fluorouracil in murine hematopoietic progenitor cells and human CD34+-enriched peripheral blood progenitor cells. Cancer Gene Ther 8:966-973. doi:10.1038/sj.cgt.7700393

Titus SA, Moran RG (2000) Retrovirally mediated complementation of the glyB phenotype. Cloning of a human gene encoding the carrier for entry of folates into mitochondria. J Biol Chem 275:36811-36817. doi:10.1074/jbc.M005163200

Toyota M, Ahuja N, Ohe-Toyota M, Herman JG, Baylin SB, Issa JP (1999) CpG island methylator phenotype in colorectal cancer. Proc Natl Acad Sci U S A 96:8681-8686

van der Straaten RJ et al (2007) Exploratory analysis of four polymorphisms in human GGH and FPGS genes and their effect in methotrexate-treated rheumatoid arthritis patients. Pharmacogenomics 8:141-150. doi:10.2217/14622416.8.2.141

Wang W, Cassidy J, O’Brien V, Ryan KM, Collie-Duguid E (2004) Mechanistic and predictive profiling of 5-Fluorouracil resistance in human cancer cells. Cancer Res 64:8167-8176. doi:10.1158/ 0008-5472.CAN-04-0970

Wang SM, Sun LL, Zeng WX, Wu WS, Zhang GL (2014) Influence of genetic polymorphisms of FPGS, GGH, and MTHFR on serum methotrexate levels in Chinese children with acute lymphoblastic leukemia. Cancer Chemother Pharmacol 74:283-289. doi:10.1007/s00280-014-2507-8

Wernimont SM et al (2012) Folate network genetic variation predicts cardiovascular disease risk in non-Hispanic white males. J Nutr 142:1272-1279. doi:10.3945/jn.111.157180

Wielinga $P$ et al (2005) The human multidrug resistance protein MRP5 transports folates and can mediate cellular resistance against antifolates. Cancer Res 65:4425-4430. doi:10.1158/ 0008-5472.CAN-04-2810

Yajnik CS et al (2008) Vitamin B12 and folate concentrations during pregnancy and insulin resistance in the offspring: the Pune Maternal Nutrition Study. Diabetologia 51:29-38. doi:10.1007/ s00125-007-0793-y

Yanagimachi $M$ et al (2011) Influence of polymorphisms within the methotrexate pathway genes on the toxicity and efficacy of methotrexate in patients with juvenile idiopathic arthritis. Br J Clin Pharmacol 71:237-243. doi:10.1111/j.1365-2125.2010.03814.x

Yao R, Rhee MS, Galivan J (1995) Effects of gamma-glutamyl hydrolase on folyl and antifolylpolyglutamates in cultured H35 hepatoma cells. Mol Pharmacol 48:505-511

Yoshinare K et al (2003) Gene expression in colorectal cancer and in vitro chemosensitivity to 5-fluorouracil: a study of 88 surgical specimens. Cancer Sci 94:633-638 